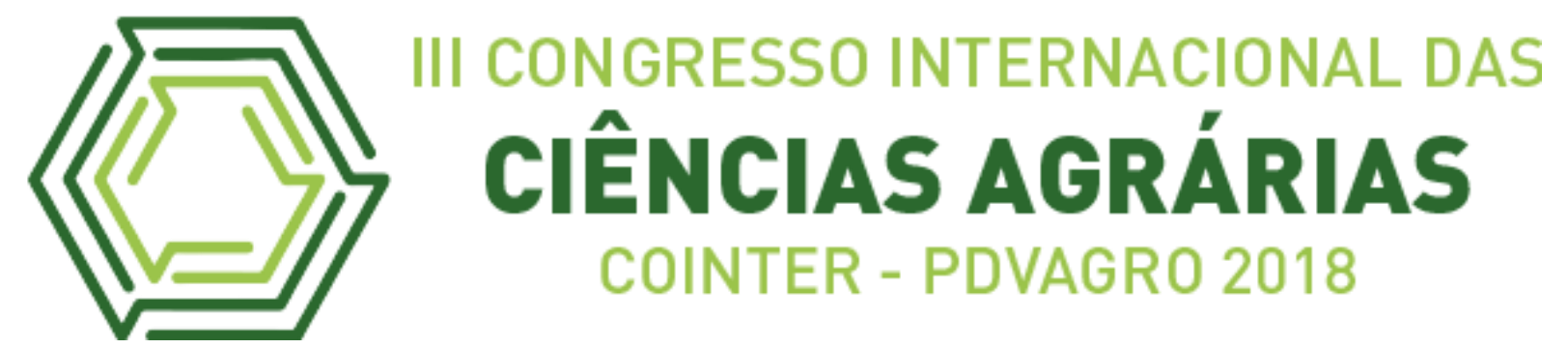

\title{
PRODUÇÃO AGROECOLÓGICA INTEGRADA E SUSTENTÁVEL: UMA EXPERIÊNCIA DIDÁTICA E PRÁTICA
}

\section{INTEGRATED AND SUSTAINABLE AGROECOLOGICAL PRODUCTION: A DIDACTIC EXPERIENCE AND PRACTICE}

\author{
Apresentação: Relato de Experiência \\ João Vitor Celerino da Silva ${ }^{1}$; Manoel Luiz da Silva Neto ${ }^{2}$; Maciel Alves Tavares ${ }^{3}$; \\ Mércia Cardoso da Costa Guimarães ${ }^{4}$
}

DOI: https://doi.org/10.31692/2526-7701.IIICOINTERPDVAGRO.2018.00765

\section{Introdução}

O sistema Produção Agroecológica Integrada e Sustentável (PAIS) visa uma agricultura sem uso de produtos tóxicos, com a preocupação de preservar o meio ambiente, integrando técnicas simples que priorizam o desenvolvimento de um sistema de cultivo que pouco dependa de insumos externos à propriedade, incentivando uma agricultura mais próxima do cultivo natural, promovendo a sustentabilidade das pequenas propriedades rurais. Principais técnicas do PAIS: sistema de irrigação por gotejamento através do uso de uma caixa d'água, utilizando a força da gravidade e proporcionando eficiência no uso dos recursos hídricos; integração da criação de aves ou pequenos animais; os resíduos produzidos por esse animais serão a matéria prima para produção, evitando assim insumos de fora da propriedade; diversificação da produção para aproveitamento dos nutrientes do solo e auxiliar no controle de pragas e doenças; quintais agroecológicos para agregar mais valor a renda familiar, através de produção de frutas, raízes e pasto para os pequenos animais ( ALY NDIAYE, 2016).

$\mathrm{O}$ aluno monitor tem como atribuição auxiliar o professor em atividades didáticaprática, na preparação de material didático e experimental, na realização de trabalhos práticos e experimentais e em atividades de classe e/ou laboratórios. Objetivou-se relatar nossa experiência como monitor da disciplina plantas forrageiras, do curso técnico em agropecuária

\footnotetext{
${ }^{1}$ Aluno do Técnico em Agropecuária, IFPE campus Vitória, vitorsjs2008@hotmail.com

2 Aluno do Técnico em Agropecuária, IFPE campus Vitória, manoel.neto9413@gmail.com

${ }^{3}$ Aluno do Bacharelado em Agronomia, IFPE campus Vitória, macieltavares15@gmail.com

${ }^{4}$ Professora, IFPE campus Vitória, mercia.guimaraes@ vitoria.ifpe.edu.br
} 
do IFPE campus Vitória de Santo Antão.

\section{Relato de Experiência}

No semestre letivo 2018.2, na disciplina plantas forrageiras, os estudantes do curso técnico integrado em agropecuária do Instituto Federal de Pernambuco Campus Vitória de Santo Antão, elaboraram e iniciaram a implantação do sistema PAIS. O objetivo das aulas era que os estudantes desenvolvessem conhecimentos e saberes sobre o Programa PAIS visando sua implantação no IFPE e em comunidades da região. Inicialmente, os alunos realizaram estudos sobre a importância do sistema nas comunidades, depois realizamos debates com estes e a professora para a aprendizagem teórica e prática.

O Programa PAIS estabelece um modelo geral de organização produtiva que tem como base a integração das produções animal e vegetal em pequenos espaços. Para isso, fizemos o desenho circular, integrando e facilitando as diferentes atividades para visualização e compreensão dos alunos. O galinheiro fica no centro, ao redor fica a horta, e o quintal agroecológico. Desta forma, gera alimento saudável e diversificado, melhorando a qualidade de vida dos produtores e consumidores. Além de contribuir para um ambiente saudável, o PAIS é adaptável a diversas regiões e à produção agrícola praticada nelas (Imagem 1).

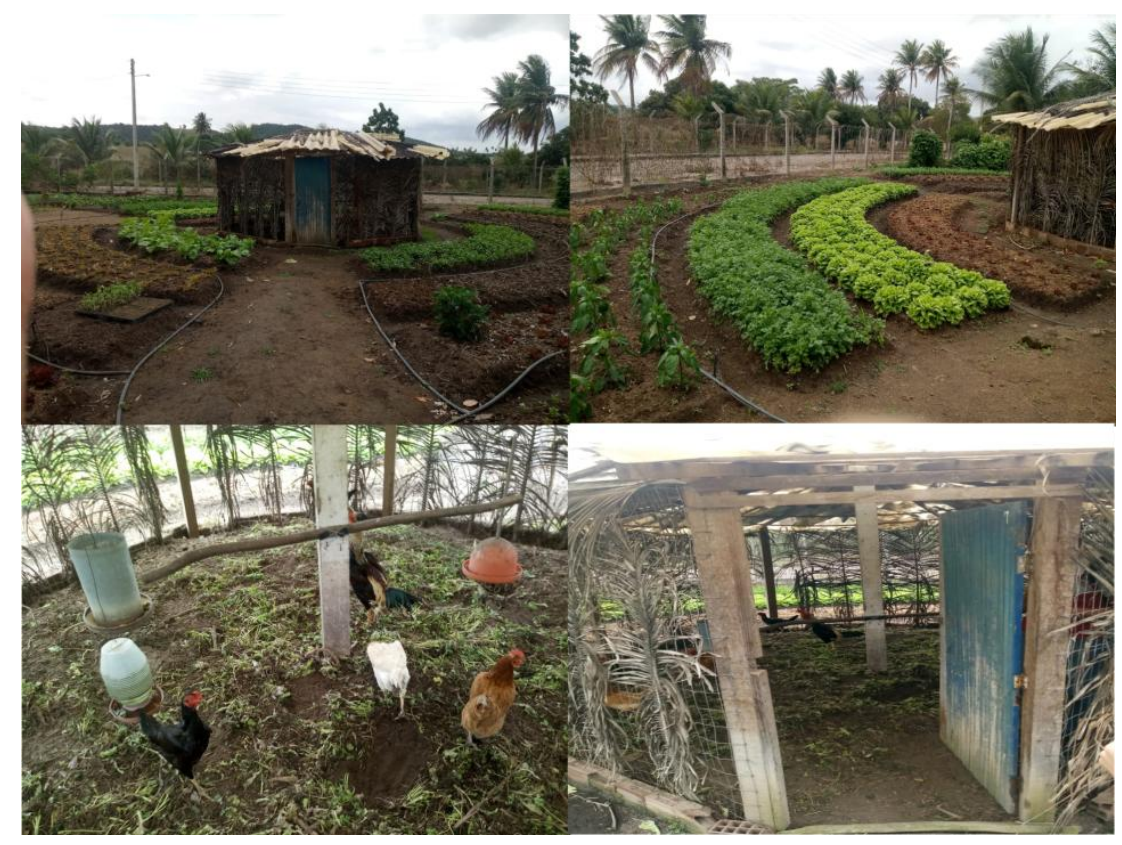

Imagem 1: Sistema PAIS do IFPE campus Vitória. Fonte: Própria. 


\section{Considerações}

Esta atividade teve como objetivo a compreensão da importância da preservação do meio ambiente e do desenvolvimento rural sustentável dentro dos princípios agroecológicos. Pudemos perceber que os conhecimentos sobre agroecologia mesmo que superficial, fazem parte da vida dos alunos, agricultores orgânicos e professores, que a relacionam à produção de alimentos orgânicos, sem agressão ao ambiente e sem o uso de agrotóxicos.

As atividades teóricas e práticas possibilitaram maior aprendizado, sendo necessário planejamento anterior para que todas as etapas fossem realizadas. A nossa participação como monitor foi importante através da interação com os alunos, conhecimentos e aquisição de novas habilidades: motivação dos grupos, segurança dos conteúdos, desempenho, liderança e paciência.

\section{Referências}

ALY NDIAYE. Análise do desenvolvimento do Programa PAIS - Produção Agroecológica Integrada e Sustentável, enquanto estratégia para geração de renda e segurança alimentar e nutricional de sistemas de produção familiares: Estudo realizado nos estados do Rio de Janeiro e Mato Grosso do Sul. Disponível em: http://cursos.ufrrj.br/posgraduacao/ppgao/files/2016/11/Aly-disserta\%C3\%A7\%C3\%A3o.pdf Acesso em: 20 desetembro de 2018.

\section{TECNOLOGIASOCIAL. PAIS - Produção Agroecológica Integrada e Sustentável.}

Disponível em http://tecnologiasocial.fbb.org.br/tecnologiasocial/banco-de-tecnologiassociais/pesquisar-tecnologias/pais-producao-agroecologica-integrada-e-sustentavel.htm Acesso em: 23 de agosto de 2018.

LUIZ CARLOS. Princípios agroecológicos na formação do técnico em agropecuária: estudo de caso da Escola Agrotécnica Federal de Vitória de Santo Antão - PE. Disponível em: http://cursos.ufrrj.br/posgraduacao/ppgea/files/2015/07/Luiz-Carlos-Alves-de-Souza.pdf Acesso em: 23 de agosto de 2018. 